Original Contribution

\title{
THE CONTRIBUTION OF READING STRATEGY AWARENESS IN L1 TO STRATEGY USE AND PERFORMANCE IN EGP AND ESP READING TASKS
}

\author{
S. H. Talebi* \\ Department of English Language and Literature, Faculty of Humanities and Social Sciences, \\ University of Mazandaran, Babolsar, Mazandaran, Iran
}

\begin{abstract}
Purpose: This study attempts to find out if reading strategy awareness in L1 (Persian) contributes to the use of these strategies and reading performance in L2 (English), both in EGP (English for general purposes) and ESP (English for specific purposes) reading tasks.

Method: 39 Iranian university students were divided into two groups of high and low degree of strategy awareness in L1, and then given reading comprehension tests as well as a reading strategy use questionnaire in EGP and ESP.

Results: Analysis of data showed: a) those who reported more awareness of strategies in L1 used more strategies in EGP and ESP reading tasks; b) high or low level of strategy awareness in L1 did not result in significant differences in ESP and EGP reading comprehension performance. c) high level awareness of reading strategies in L1 made learners have a better attitude toward reading in EGP and ESP reading tasks.

Conclusion: It is concluded that L1 teachers should take reading strategy instruction in L1 serious as it will affect the process of reading in L2 and give the students a better attitude toward reading in L2. Moreover, ELT practitioners should introduce more texts in L2, so students use these strategies effectively while reading in $\mathrm{L} 2$.
\end{abstract}

Key words: reading strategies, reading performance, EGP, ESP, CUP

\section{INTRODUCTION}

Content-based instruction of reading is one of the most effective approaches of ESL instruction where language instruction is integrated with the content areas. In content reading, prior knowledge contains both knowledge about the topic, and strategic schema which includes knowledge about strategies (declarative), knowledge about how to deploy them (procedural), and knowledge about when and where to apply the strategies (conditional) (1). In content-based courses, reading involves not only understanding content, but also processing strategies in order to understand content. Reading strategies have been defined as specific, deliberate, goaldirected mental processes or behaviours, which control and modify the reader's efforts to

\footnotetext{
*Correspondence to: Seyed Hassan Talebi, Department of English Language and Literature, Faculty of Humanties and Social Sciences, University of Mazandaran, Babolsar, Mazandaran, Iran, Tel No: 00989112187707; email address: hstalebi@umz.ac.ir
}

decode a text, understand words and construct the meaning of a text (2). The massive expansion of scientific, technical and economic activities on an international scale of the 1950s and 1960s resulted in ESP teaching as an approach in ELT (3). The ESP methodology takes into consideration the specific needs and demands of learners in real communication in English. It builds on EGP research and a solid understanding of basic EGP should precede instruction in ESP, if ESP programs are to yield satisfactory results (4). EGP builds up the foundation of general English skills such as skimming, scanning, and making predictions in different genres.

The debate over whether reading instruction through L1 improves reading performance in L2 (English) raised the question of whether reading ability in the primary language transfers to the second language. Two hypotheses, the Common Underlying Proficiency Hypothesis (CUP) and the Reading Universal Hypothesis, claim that reading is a skill interdependent or universal across 
languages. According to Cummins' (5) CUP skills transfer from the first language to the second language and that knowledge of the first language and how language works will transfer to the second language resulting in the enhancement of its acquisition. In the reading universal hypothesis, as has been addressed by Goodman (6) in his psycholinguistic point of view, the primary goal of reading is comprehension. Goodman (6) argues that the reading process will be much the same for all languages and the key question is how much background knowledge the reader brings to the specific reading task. However, Yorio (7) takes an opposite view. He mentions "the readers' knowledge of foreign language is not like that of the native speaker, the guessing or predicating ability necessary to pick up the correct cues is hindered by the imperfect knowledge of the language".

As Dreyer and Nel (8) mention university students of English as a second or foreign language have to read a large volume of academic texts in English as many students enter university education underprepared for the reading demands placed on them. They often present low level of reading strategy knowledge and lack the strategies needed to successfully comprehend expository texts. In another study, Ahmadi (9) focused on whether or not ESP reading performance can be tested by EGP reading. He found a positive correlation between the scores of candidates in the ESP and EGP tests, maintaining that EGP tests seem to be good measures for ESP competency. However, literacy in L1 reading is an important factor that affects reading in L2. In fact, as ESP reading might be influenced by experiences in EGP reading, the EGP reading by itself might be influenced by reading experience in first language. The strategic approach to reading in L1 may help us predict the strategic reading behaviors in
ESP and EGP reading tasks. Therefore, this study is guided by the following research questions:

1. Do students of high level awareness of L1 (Persian) reading strategies differ from students of low level awareness of L1 reading strategies in EGP and ESP reading strategies use?

2. Do students of high level awareness of L1 (Persian) reading strategies differ from students of low level awareness of L1 reading strategies in EGP and ESP reading ability?

3. What is the perception of Iranian EFL learners of high and low level of reading strategy awareness in L1 toward reading in EGP and ESP?

\section{METHODOLOG}

\section{PARTICIPANTS}

Thirty nine tertiary level BA students who were predominantly freshmen and sophomores at the University of Mazandaran participated in this study. They were enrolled in the English for General Purposes (EGP) Course and their major areas of study were mathematics and computer Engineering. Hardin (10) found that strategic behaviors in L1 undergird L2 reading behaviors and that the level of second language proficiency played a less prominent role in second-language strategic reading than did the level of strategy use in L1. Therefore, in this study in order to divide subjects into two groups of low and high reading strategy awareness in L1, a check-list of reading strategies was employed. Those who scored below the mean score were considered low group and those who scored above the mean score were considered high group. (Table 1) For the purpose of the retrospective interview two students, one from the low group and one from the high group were selected randomly. They were 20 years old.

Table 1. Mean and standard deviation of questionnaire scores in Persian reading strategies

\begin{tabular}{lllll}
\hline Index & & M & SD & N \\
\hline Persian & High & 132.00 & 13.08 & $\mathbf{2 1}$ \\
questionnaire & Low & 103.66 & 10.02 & $\mathbf{1 8}$ \\
& Total & 118.92 & 18.43 & $\mathbf{3 9}$ \\
\hline
\end{tabular}

\section{INSTRUMENTS}

\subsection{Reading strategy questionnaire}

According to Chamot (11) there are a number of methods that have been used to find out the best language learning strategies, but the most frequent is through questionnaires. In this study, the strategic approach (awareness and use of reading strategies while reading) was measured by means of a five-point Likert scale reading strategy questionnaire (Never/Seldom/ Sometimes/ Usually/ and Always true of me) offering an immediate retrospective picture of the reading behavior. The strategy questionnaire was in Persian so that students 
felt more comfortable with the questionnaire while answering. The students were informed that it was not a test to have effects on their final marks, and that there were no right or wrong answers. All the thirty three items (cognitive and metacognitive) of this instrument were adapted from different related questionnaires in research-validated studies $(12 ; 13 ; 14)$. The questionnaire was finally shown to two experts in the field for getting their opinion about strategy items to see if they suited the purpose of the study. These two experts were Ph.D. holders in applied linguistics with some ten years of teaching experience at university at BA and MA levels. The two experts were also asked about the translated version of the instrument. The internal consistency reliability coefficient of the instrument at the piloting stage was calculated to be 0.83 as it was piloted against 15 students taking part in the study.

This instrument had two purposes. First, it was used to homogenize the participants based on reading strategy awareness in L1 (Persian). Second, it was employed to assess reading strategy use in EGP and ESP reading tasks.

\subsection{Reading tests}

\section{A: Test of Reading Comprehension in Persian}

The reading comprehension test in Persian had two passages, each containing fifteen items (30 items in total). The nature of the items in terms of recognizing main ideas, vocabulary knowledge, and inferencing was the same for the two passages. The two passages of the test were selected from the book Bahar va Adab-eFarsi. After administering this test to a similar group of fifteen students, the reliability of the scores of this test according to the KR-21 formula at the piloting stage was calculated to be 0.75 . This test was also shown to two experts in Persian language and literature teaching in order to have their comments on the suitability of the text as well as on the nature of the test items for the students. The time allotted for the reading test in Persian was 30 minutes as determined at the piloting stage.

\section{B: Test of Reading Comprehension in English (for general purposes)}

In developing the test of reading comprehension in English five passages were selected from the reading section of books two and three of the New Interchange series. The number of words in each of the selected five passages ranges from 257 to 295 words. Six items were developed for each passage, and all in all there were thirty items for all the five passages. The nature of the items in terms of recognizing main ideas, vocabulary knowledge, and inferring was the same for all the passages. The reliability of the test of reading in English was also taken care of at the piloting stage through the K-R21 formula which turned out to be .76 . The time allowed was 30 minutes as determined at the piloting stage .

\section{C: Test of Reading Comprehension in English (for specific purposes)}

In developing the test of ESP reading comprehension in English two passages were selected. The first passage titled 'What is information processing?' from the reading section of 'English for Students of Computer', by Haghani (15) and the second passage titled 'The Need for Accounting' from 'English for the Students of Accounting' by Aghvami (16). Each passage contained 10 items. The number of words in the selected two passages ranged from 610 to 560 words. These texts were nearly of the same difficulty in terms of structure, unknown words and cognitive processing as it was approved by two experts in the field. The reliability of the test of reading in English was also taken care of at the piloting stage through the K-R21 formula which turned out to be 0.79 . The time allowed was 30 minutes as determined at the piloting stage .

\subsection{Interview protocol on reading in EGP and ESP}

In order to capture the different perceptions that low and high groups of L1 reading strategies had toward the reading strategy use and reading performance in EGP and ESP and to complement the findings of the survey study, the researcher gave a one-on-one semistructured interview with two participants, using open-ended questions.

It is to be noted that in the background questionnaire obtaining demographic information about the participants, the two students perceived their proficiency to be at an average level and their reading skill was more advanced than other skills. The interview for each student took about 15 minutes. All interviews were audio recorded with the students' consent. The interview questions fell mostly into two categories. One was on reading ability and the other was on the strategies they utilized in reading EGP and ESP texts.

\section{PROCEDURE}

This study is both qualitative and quantitative in nature. Therefore, it has a mixed-methods design. For the quantitative phase of the study, 
the reading strategies questionnaire and the three tests of reading comprehension were administered to students during the regular class time. After a brief explanation of the purpose of the study, participants were given instructions on how to answer the questionnaire and reading test batteries. They were instructed to take a reading test in Persian as a trigger so that they could report the strategies they were aware of while reading in their $\mathrm{L} 1$ reading. The students were also advised there was time limitation for the reading tests but not for the reading strategies questionnaire. After a two-week interval the subjects took the second reading test which was the EGP reading test followed by the reading strategy questionnaire as a retrospective measure, showing what reading strategies students would use while reading in EGP. Then, after another two-week interval the ESP reading comprehension test was distributed to students as a retrospective measure showing what reading strategies students would use while reading in ESP. As was mentioned there was no time limit on answering the questionnaire and the researcher would answer any possible questions for more clarity so that the data were liable for the analysis purposes.

For the quantitative phase of the study interviews were conducted for assessing students' perception of reading in EGP and
ESP. The interviews were conducted in Persian as both the participants and the researcher felt more comfortable and expressive in Persian and it was believed that more accurate data would be collected. The recordings were transcribed and translated from Persian to English language. In data analysis the data were coded and divided into segments with similar characteristics. To have more accurate and correct data, a colleague who is a Ph.D. in applied linguistics was asked to review transcriptions.

\section{DATA ANALYSIS}

In this section, first the research questions are mentioned and the analysis of data will be provided.

\section{Do students of high level awareness of Persian reading strategies differ from students of low level awareness of Persian reading strategies in EGP and ESP reading strategies use?}

Analysis using multivariate analysis of variance (Wilks' Lambda) for unrelated measures revealed a significant main effect of the Persian reading strategies at an alpha of .05 , Wilks' Lambda $=.75, F(2,36)=5.88, p=$ .006 . This means that the high group used more strategies in EGP and ESP reading tasks in contrast to low group. A measure of effect size, $\eta^{2}=.24$, indicated a relatively large effect (Table 2).

Table 2. Multivariate test of Persian reading strategies groups (high or low) on EGP and ESP reading strategy use

\begin{tabular}{llllllll}
\hline Effect & Value & F & $\begin{array}{l}\text { Hypothesis } \\
\text { df }\end{array}$ & $\begin{array}{l}\text { Error } \\
\text { df }\end{array}$ & sig & Eta \\
\hline $\begin{array}{l}\text { Persian reading } \\
\text { strategies }\end{array}$ & $\begin{array}{l}\text { Wilks' } \\
\text { Lambda }\end{array}$ & .75 & 5.88 & 2 & 36 & .006 & .24 \\
\hline
\end{tabular}

To find out which of the variables differed, test of between-subject effects was used. This test indicated that reading strategy use is significantly different both in EGP and ESP reading tasks, in Persian reading strategies groups (high or low) (Table 3).

Table 3. Between-subject test of Persian reading strategies groups (high or low) on EGP and ESP reading strategy use

\begin{tabular}{llllllll}
\hline Source & $\begin{array}{l}\text { Dependent } \\
\text { variable }\end{array}$ & DF & SS & MS & F-ratio & sig & Eta \\
\hline Model & EGPQ & 1 & 5604.94 & 5604.94 & 11.51 & .002 & .23 \\
& ESPQ & 1 & 3493.07 & 3493.07 & 8.08 & .007 & .17 \\
\multirow{5}{*}{ Error } & EGPQ & 37 & 18004.95 & 486.62 & & & \\
& ESPQ & 37 & 15981.58 & 431.93 & & & \\
\hline \multirow{2}{*}{ otal } & EGPQ & 39 & 1163325.00 & & & & \\
& ESPQ & 39 & 505783 & & & & \\
\hline
\end{tabular}

With respect to mean differences, the high group had a higher mean score in EGP and
ESP reading strategies use than the low group.

(Table 4) 
TALEBI S. H.

Table 4. Mean and standard deviation of EGP and ESP reading strategy use with respect to Persian reading strategies groups

\begin{tabular}{llllll}
\hline Source & Dependent V & Index & M & SD & N \\
\hline Farsi Q group & EGPQ & High & 182.04 & 23.63 & 21 \\
& & Low & 158.00 & 20.04 & 18 \\
& ESPQ & High & 120.43 & 23.17 & 21 \\
& & Low & 101.44 & 17.56 & 18 \\
\hline
\end{tabular}

2. Do students of high level awareness of Persian reading strategies differ from students of low level awareness of Persian reading strategies in EGP and ESP reading ability?

Analysis using multivariate analysis of variance (Wilks' Lambda) for unrelated measures revealed a non significant main effect of the manipulation of Persian reading strategies at an alpha of .05 , Wilks' Lambda $=$ $.05, F(2,36)=.88, p=.423$. This means that both EGP and ESP reading ability was the same in high and low level of Persian reading strategies. A measure of effect size, $\eta^{2}=.047$, indicated a relatively low effect. (Tables 5-6)

Table 5. Mean and standard deviation of EGP and ESP reading ability with respect to Persian reading strategies groups

\begin{tabular}{llllll}
\hline Source & Dependent V & Index & M & SD & N \\
\hline Farsi Q group & EGPR & High & 10.28 & 3.60 & $\mathbf{2 1}$ \\
& & Low & 9.88 & 3.39 & $\mathbf{1 8}$ \\
& \multirow{2}{*}{ ESPR } & High & 8.38 & 3.59 & $\mathbf{2 1}$ \\
& & Low & 7.05 & 2.50 & $\mathbf{1 8}$ \\
\hline
\end{tabular}

Table 6. Multivariate test of Persian reading strategies groups (high or low) on EGP and ESP reading ability

\begin{tabular}{llllllll}
\hline Effect & & Value & F & $\begin{array}{l}\text { Hypothesis } \\
\text { df }\end{array}$ & $\begin{array}{l}\text { Error } \\
\text { df }\end{array}$ & Sig. & Eta \\
\hline $\begin{array}{l}\text { Persian reading } \\
\text { strategies }\end{array}$ & $\begin{array}{l}\text { Wilks' } \\
\text { Lambda }\end{array}$ & .05 & .88 & 2 & 36 & .423 & .047 \\
\hline
\end{tabular}

Research Question 3: What is the perception of Iranian EFL learners of high and low level of reading strategy awareness in L1 toward reading in EGP and ESP?

When asked to elaborate on strategic reading behavior in EGP and ESP the Low Level Student mentions reading in EGP and ESP is not different because he is week at both. He has the same strategies in mind for reading these texts as he thinks EGP and ESP texts are the same in structural organization and difficult vocabularies. Because of this he is stressful when it comes to reading such difficult passages. About this question the High Level Student mentions the reading process in EGP and ESP is the same as he employs the same strategies in both. He thinks as ESP texts are content familiar they cause less stress in comprehension.
Regarding the question asking which strategies are easy or difficult to be employed while reading in ESP or EGP, the Low Level Student believes strategies that are related to vocabulary and grammar are more difficult to employ while reading. In general, he believes he is not very fluent in strategy use in EGP and ESP. In fact, the problem is that he does not use strategies very well. On the other hand, the High level Student mentions metacognitive strategies are less familiar to him and that he does not know how to use them practically in his reading in English, both in EGP and ESP. He claims to have this kind of behavior in his mother tongue, as well.

When asked if they use any strategies when encountering a language problem in a text both in EGP and ESP, the Low level student mentions the problem is that he does not have a good knowledge of vocabulary or grammar 
and does not know how to tackle these problems. On this question the High level Student mentions he uses strategies, such as guessing the meaning of unfamiliar words through context in EGP and ESP reading. However, he feels more comfortable and at ease with ESP texts as the content is more familiar to him in ESP texts.

When asked if they would you like to have the instruction of reading strategies in EGP and ESP curriculum, although the Low level student Okays it, he believes it is better if students expand their knowledge of vocabulary and grammar. The High level student also Okays it but he believes metacognitive strategies are very important to be taught.

When asked if they have the same performance in EGP and ESP reading tasks the Low level student claims he thinks there is no difference in reading performance in EGP and ESP as the same vocabulary and grammatical problems that he thinks to have in EGP exist in his ESP reading, as well. The High level student thinks he is relatively good at both and reads ESP and EGP texts at the same speed and fluency. He also claims to enjoy reading in both as he claims he is more in need of specialized articles and books in his academic life. He thinks as he is familiar with the content he can better understand texts in ESP and feels less worried to start reading in ESP compared to EGP. But in general as he thinks the way of reading in EGP and ESP is the same he is at ease with both EGP and ESP reading.

When asked which part is easy or difficult: Grammar, Vocabulary, or other language components, the Low level student thinks in both EGP and ESP the vocabulary and grammatical problems are challenging and difficult to solve. Therefore, he does not see any distinction. He does not know how to solve a problematic sentence in English mostly because of his limited vocabulary size and knowledge of English grammar. To this question the High level Student believes he is at ease with both EGP and ESP readings as his awareness of reading strategies is good and helps him confront the difficulties in reading; while reading in EGP or ESP he tries to get the meaning by using the words whose meaning he knows. However, because of content familiarity in ESP texts, before starting reading in ESP, he thinks he can understand it. Therefore, he has good selfconfidence in ESP reading. This does not happen in his EGP reading. He thinks it is best if English language teachers do not focus much on the mechanics of language and in return teach us how to learn the different skills (such as reading and writing) and sub-skills (such as grammar and vocabulary).

\section{DISCUSSION AND CONCLUSIONS}

This study had different findings based on data collected qualitatively and quantitatively.

Based on interview analysis, the data regarding the perceptions of the two students toward reading in EGP and ESP can be classified into three categories: reading process, reading product, and affective factors in EGP and ESP.

\section{Reading process:}

Regarding the process of reading or the mental processes involved in reading, both the Low and High Level Student mentions they have the same strategies in mind for reading texts in EGP and ESP; however, the reason for this for the Low Level Student is that he thinks EGP and ESP texts are the same in structural organization and difficult vocabularies. To the low level student strategies that are related to vocabulary and grammar are more difficult to employ while reading, while the High level Student mentions metacognitive strategies are less familiar to him and that he does not know how to use them effectively in his reading in EGP and ESP. The Low level student mentions he does not know how to tackle these problems. The High level Student mentioned in order to tackle the reading problems he uses strategies, such as guessing the meaning of unfamiliar words through context in EGP and/or ESP reading. The Low level student believes vocabulary and grammar are very important to be worked upon, but The High Level Student believes metacognitive strategies are very important to be taught. To him awareness of reading strategies helps him confront the difficulties in reading;

\section{Reading product:}

The Low Level Student mentions his language problem is that he does not have a good command of vocabulary or grammar and does not know how to tackle these problems. He thinks EGP and ESP texts are the same in structural organization and difficult vocabularies. He makes no distinction between EGP and ESP texts and finds a common problem in them which is the mechanics of them. He believes it is better if students expand their knowledge of vocabulary and grammar. The High Level 
Student thinks ESP texts are different from EGP texts as ESP texts are familiar to them in terms of content.

\section{Affective factors in reading}

One interesting finding that emerged from the interview data analysis is related to the affective domain. The Low Level Student is stressful when it comes to reading because of his low knowledge of vocabulary and grammar but the High Level Student mentioned he feels more comfortable and at ease with ESP texts as ESP texts are content familiar they cause less stress in comprehension. The Low Level Student has a good attitude toward learning vocabulary and grammar to read effectively in EGP and ESP. But the High Level Student has a good attitude toward improving his knowledge of metacognitive strategies. He enjoys reading both in EGP and ESP as he is in need of specialized articles and books in his academic life. He thinks as the way of reading in EGP and ESP is the same he is at ease with both EGP and ESP reading. However, because of content familiarity in ESP texts, before starting reading in ESP he thinks he can understand it. Therefore, he has good selfconfidence in ESP reading. This does not exist in his EGP reading.

Regarding the questionnaire survey it has been found that the high and low group students differ significantly in reported strategies use in ESP and EGP reading tasks. In other words, those who have more awareness of reading strategies in L1 reading tasks use more reading strategies in EGP and ESP reading tasks.

Regarding the reading performance, it was found that high or low level of strategy awareness in L1 does not result in significant differences in ESP and EGP reading comprehension performance. In fact, low or high level of awareness of strategies in L1 does not differentiate between readers in performing ESP and EGP reading tasks.

The different findings of this study have supports in the literature. Cummins' (5) common underlying proficiency hypothesis (CUP) and Goodman's (6) reading universal hypothesis claim that reading is a skill interdependent or universal across languages. Cummins claims that students who have developed literacy in their first language will tend to make stronger progress in acquiring literacy in their second language (5).This finding also supports views held by Bossers (17) and Coady (18) and Jimenez, et al (19) who regard a unitary view for the process of reading in different languages. Bossers (17) believes that if students are strategic in their first language, there is a strong possibility that the strategies they use with their mother tongue, when brought to their attention, may transfer from one language to another. Coady (18) asserts that foreign language reading is a reading problem that readers have in their L1 and not a language problem. Jimenez, et al. (19) found that bilingual readers tended to have a unitary view of reading and conceive many similarities between reading in Spanish (L1) and English (L2).

According to Sheorey and Mokhtari (13), it is the combination of conscious awareness of the strategic reading processes and the actual use of reading strategies that distinguishes the skilled from the unskilled readers. This fact is described by Cook (20) as "cognitive processes work less efficiently through the second language. L2 learners have 'cognitive deficits' with reading that are not caused by lack of language ability but by difficulties with processing information in L2".

Studies in L1 and L2 contexts show that unsuccessful students lack this strategic awareness and monitoring of the comprehension process (21). These less successful students, who are often unaware of their own cognitive process, must be helped to acquire and use the reading strategies that have been found to be successful (22).

Implications can be drawn from this study. One is that teaching readers how to read strategically in L1 should be a prime concern in L1 reading classrooms. In addition, rather than focusing students' attention solely on learning the language mechanics, second language teachers can help students learn to think about what happens during the language learning process, which will lead them to develop stronger learning skills(23). Therefore, we should help learners develop strategic reading behavior in their native language and to transfer them to reading task in the second language.

Another implication for this study is that in order to see the effects of reading strategy awareness in L1 on EGP and ESP reading performance we need to expose our readers to a variety of EGP and ESP reading tasks so that they apply their knowledge of strategic reading in a different code that is English. Mere awareness and use of strategies in L1 does not guarantee reading success in L2. It is the effective use of strategies that 
differentiates skilled readers from unskilled readers.

The present study showed a positive correlation between strategic competence of Iranian EFL learners in L1 and L2 (EGP and ESP). However, it failed to find a positive relationship between strategic competence in L1 with reading scores in L2 EGP and ESP reading tasks. This might depend on factors such as general linguistic proficiency level, task difficulty, and affective factors (such as L2 learning attitude, attitudes toward reading in L1 and L2 (24), motivation to learn L2, self-efficacy, learners' beliefs, and selfconfidence in L2 learning). It is a good area for further research to see if and to what extent these variable correlate with successful reading in L2 general and specific reading tasks.

\section{REFERENCES}

1. Paris, S. G., Cross, D. R., \& Lipson, M. Y., Informed strategies for learning: A program to improve children's reading awareness and comprehension, Journal of Educational Psychology, 76:1239-1252, 1984.

2. Afflerbach, P., Pearson, P. D., \& Paris, S. G., Clarifying differences between reading skills and reading strategies. The Reading Teacher, 61: 364-373, 2008.

3. Dudley-Evans, T, \& M.J. St. John., Developments in English for Specific Purposes. Cambridge: Cambridge University Press, 1998.

4. Hutchinson, T., \& Waters, A., English for specific purposes: A learning centered approach. Cambridge: Cambridge University Pres,. 1987.

5. Cummins, J., Language, Power and Pegagogy. Clevedon: Multimlingual Matters, 2000.

6. Goodman, K. S., Reading: A psycholinguistic guessing game. In: Singer H, Ruddell RB (ed). Theoretical models and processes of reading. Newark, DE: International Reading Association, 1970.

7. Yorio, C., Some sources of reading problems in foreign language learners, Language Learning. 21(2): 108, 1971.

8. Dreyer, C. \& Nel, C., Teaching reading strategies and reading comprehension within a technology-enhanced learning environment. System, 31: 349-365, 2003.

9. Ahmadi, M., Can ESP be tested by EGP, Journal of Medical Education, 3: 7-10, 2003.

10. Hardin, V. B., Transfer and Variation in Cognitive Reading Strategies of Latino Fourth-Grade Students in a Late-Exit
Bilingual Program. Bilingual Research Journal, 25(4), 2001.

11. Chamot, A. U., Issues in Language Learning Strategy Research and Teaching Electronic Journal of Foreign Language Teaching, 1(1): 14-26, 2004.

12. Oxford, R, L., Yunkyoung Cho, Santoi Leung, \& Hae-Jin Kim., Effect of the presence and difficulty of task on strategy use: An exploratory study. In: Peter, IJ, Kellerman E (eds), pp 42(1): 1-47, 2004.

13. Sheorey, R. \& Mokhtari, K., Differences in the Metacognitive Awareness of Reading Strategies among Native and Non-native Readers, System, 29 (4): 431-449, 2001.

14. Taillefer, G. \& Pugh, T., Strategies for professional reading in L1 and L2, Journal of Research in Reading, 21(2): 97-108, 1998.

15. Haghani, M., English for Students of Computer. The Centre for Studying and Compiling University Books (SAMT), 2001.

16. Aghvami, D., English for the Students of Accounting,.SAMT Publications, 1996.

17. Bossers, B., On Thresholds, Ceilings and Short-Circuits: The Relation between L1 reading, $\mathrm{L} 2$ reading and $\mathrm{L} 2$ knowledge. AILA Review, 1991.

18. Coady, J., Psycholinguistic model of the ESL readers. In: Mackay R. Barkranand B., Jordon, $\mathrm{R}$ (eds), Reading in a second language: Hypothesis, organization and practice. Rowley, MA: Newbury House, pp 5-12, 1979.

19. Jimenez, R., Garcia, G., \& Pearson, P., Three children, two languages, and strategic reading: case studies in bilingual/monolingual reading. American Educational Research Journal, 32 (1): 6797, 1995.

20. Cook, G., "Viewpoint. A Thing of the Future: Translation in Language Learning."International Journal of Applied Linguistics, 17(3): 396-401, 2007.

21. Garcia, G. E., Willis, A. I., and Harris, V. J., Appropriating and creating space for difference in literacy research. Journal of Literacy Research, 30: 181-186, 1998.

22. Mokhtari, K. \& Reichard, C., Investigating the strategic reading process of first and second language readers in two different cultural contexts. System, 32, 379-394, 2004.

23. Anderson, N. J., The Role of Metacognition in Second Language Teaching and Learning. EricDigest,EDO-FL-01-10, retrieved September 23, 2012 from http://www.cal.org/resources/digest/digest_p dfs/0110_Anderson.pdf

24. Yamashita, J., Reading attitudes in L1 and L2, and their influence on L2 extensive reading. Reading in a Foreign Language, 16, 1-19, 2004. 